\title{
Testing the Validity of "Old Wives Tales" About Fixation of Tissue Cultured Cells
}

\author{
Patricia Stranen Connelly ${ }^{1}$
}

${ }^{1}$ Department of Health and Human Services, National Institutes of Health, National Heart, Lung and Blood Institute, Bethesda, MD 20892.

Over the years, many ideas have been handed down from one technologist to another about what to do and what not to do when fixing cells and tissues. This set of experiments takes into account certain conditions involving the age of the prepared primary fixative, length of time in primary fixative, length of time en bloc stain is on tissue cultured cells and the effect of washing the cells before fixation with phosphate buffered saline (PBS).

Cells chosen for this set of experiments were human umbilical vein endothelial cells (HUVEC) fixed in $2.5 \%$ glutaraldehyde, $1 \%$ paraformaldehyde in $0.12 \mathrm{M}$ sodium cacodylate buffer $\mathrm{pH} 7.3$ initially at room temperature. Our standard protocol is to fix for $20 \mathrm{~min}$ then cool down on ice or refrigerate for $40 \mathrm{~min} ; 1$ hour buffer washes; $1 \%$ osmium tetroxide; buffer wash; water wash; overnight in 1\% uranyl acetate; graded ethanol dehydration, infiltration and embedding in Epon made with LX-112 (Ladd Research Industries); cure at $60^{\circ} \mathrm{C}$ for 2 days. The conditions tested were as follows:

a. Cells fixed and held in a refrigerator 3 days (over weekend) before processing

b. Cells fixed in 3 day old fixative and processed the same day

c. Cells fixed in fresh fixative and processed the same day

d. Cells fixed in fresh fixative after PBS wash, processed the same day

e. Cells fixed in fresh fixative, held overnight at $4^{\circ} \mathrm{C}$, processed 1 hour UA en bloc stain

The images from conditions $a, b$, and c show no structural differences as seen in Figure 1. This indicates that the HUVEC cells processed in our lab, having been held over a weekend or with fixative that was made a few days prior to use, are as well preserved as those that arrived during the week and were processed according to our standard protocol. These HUVEC cells were only moderately affected by a PBS wash before fixation. The only differences detected were a more irregular contour of the inner nuclear membrane in some cells washed with PBS before fixation and the appearance of approximately twice the number of cells containing swollen mitochondria or ones with large empty areas (Figure 2). The lack of other differences in the PBS washed cells was an unexpected observation in view of my past observations with other types of cells. This leads to future investigation using different cell types and perhaps different buffer systems.

The most notable difference was found between the cells en bloc stained with uranyl acetate for an hour versus overnight. For both conditions, thin sections were stained for 10 min with 1\% UA in 50\% ethanol, washed and lead citrate [1] stained for $3 \mathrm{~min}$. There was less contrast in the $1 \mathrm{hr}$ en bloc stained cells, but the ultrastructure was comparable to that obtained with overnight en bloc stain (Figure 3) [2].

References:

[1] A Fahmy, Proceedings of the Electron Microscopy Society of America (1967), p. 148.

[2] The author acknowledges support from the Division of Intramural Research of the NHLBI, NIH. Drs. Kumiko and Takehiro Torisu are thanked for kindly supplying the HUVEC cells. 

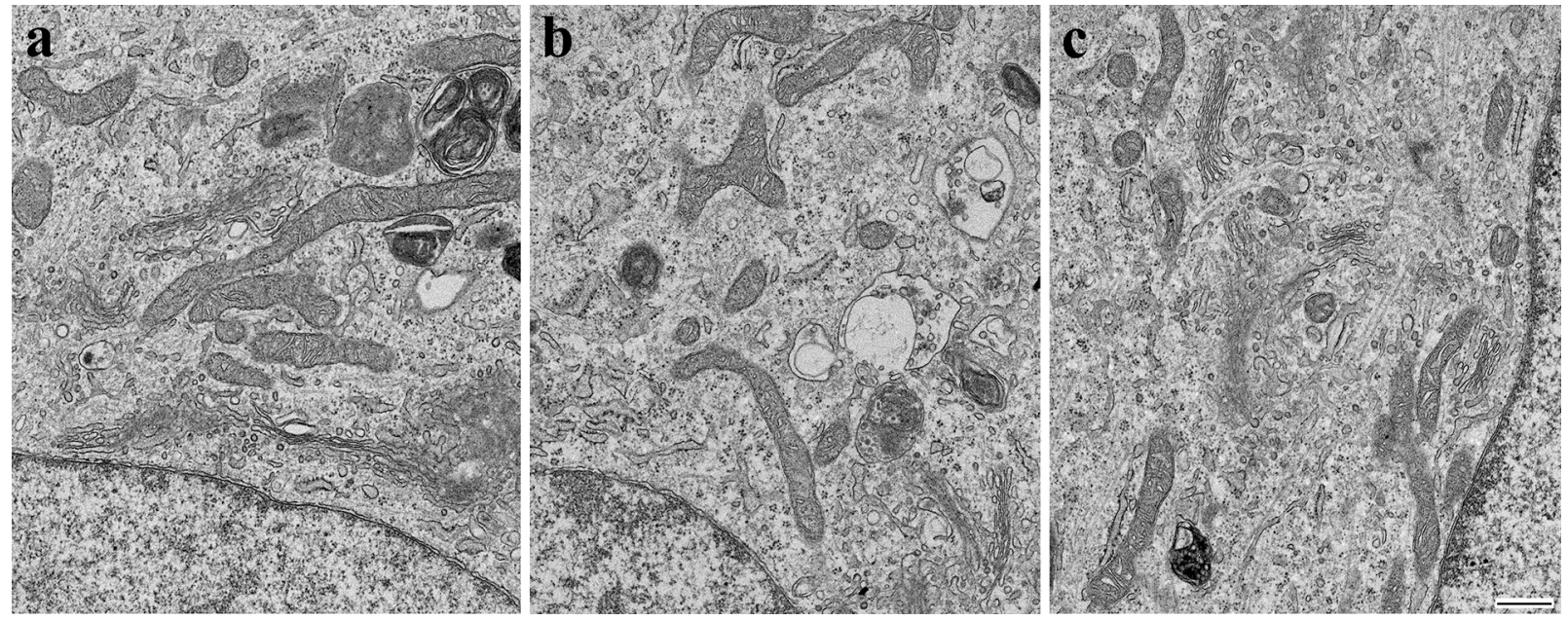

Figure 1. Conditions a, cells held in fixative over a weekend, b, 3 day old fixative and c, control showing no morphological differences. Bar: $500 \mathrm{~nm}$.
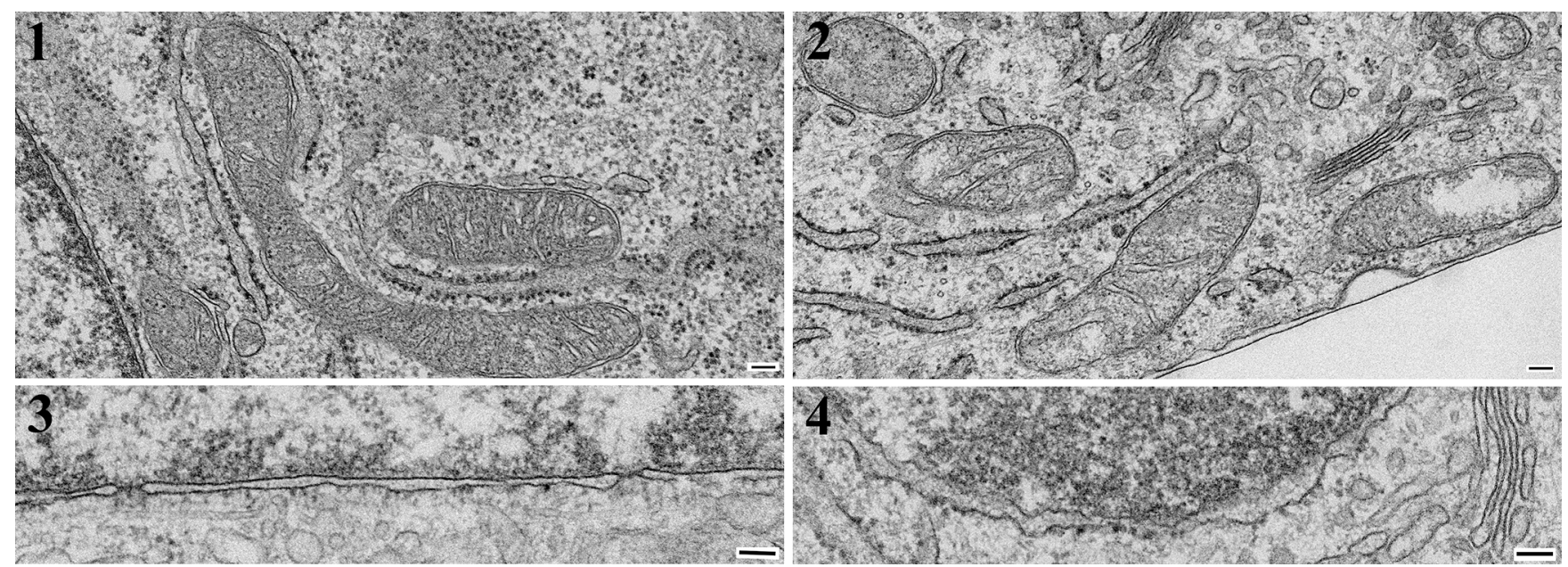

Figure 2. In the upper panels the control (1), and cells washed in PBS before fixation (2), are represented showing the difference in the mitochondrial morphology. The condition of the inner nuclear membrane in the control (3) is straight while washing with PBS causes a ruffling of the inner nuclear membrane (4). Bars: $100 \mathrm{~nm}$.
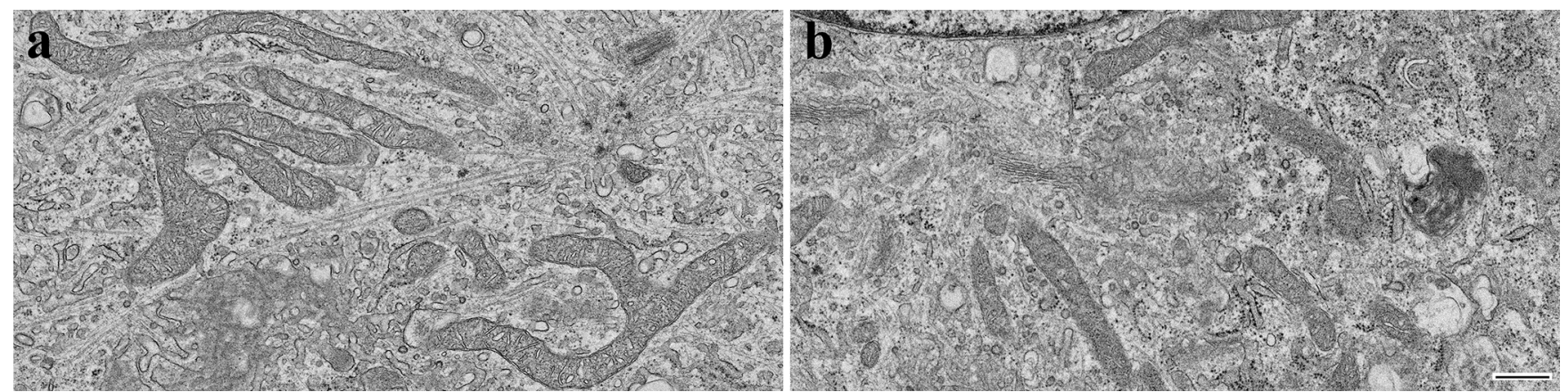

Figure 3. The membranes of cells in UA for 1 hour (b) have less contrast than those of the control (a). Bar: $500 \mathrm{~nm}$. 